\title{
The Research and Practice on Educational Reform of Landscape Design
}

\author{
Xiaodong Zhang
}

Department of Environmental Art Design, Hebei Institute of Fine Art ,ShiJiaZhuang HeBei, 050700, China

Keywords: indoor rendering, 3D design, teaching method

\begin{abstract}
The Landscape Design plays an important role in the teaching system of environmental art design. Art design opened since 2001 in our school, mainly faces students with three years of higher vocational in the school system, which has accumulated certain experience in teaching. But with the rapid development of the environmental art design, landscape industry, market and society have new demand for graduates, the old teaching content of the course, teaching method and examination method in some aspects, such as already can not adapt to the requirements of new situation based on the course characteristics and the development of landscape ecology pattern, analyses the current development of landscape ecology and characteristics that existing in the teaching reform is not prominent insufficient standard, so as the teaching material, at the same time the practice is weak, lack of teaching resources and so on, we explore the subject architecture and landscape ecology construction from horizontal integration and vertical two aspects, and put forward the thinking of teaching reform and construction of Landscape Design with these aspects, the knowledge system construction of the discipline ,the practice teaching content, fusion of teaching method. How to do a better job in the course of teaching under the challenges and opportunities co-exist today, which has become a problem we have to think about.
\end{abstract}

\section{Background of Teaching}

To master a set of scientific and practical methods and software operating skills are necessary, which is directly related to making the final outcome, also directly affect the students' learning enthusiasm and subjective initiative. Students how to learn the software within the limited class hours, and reach certain teaching effect, is worthy of professional teachers think seriously about. Relative to the cultivation of higher vocational colleges and universities career guidance, technical secondary school at the university of education on the quality and ability training as the guide, for ring arts major, which is to cultivate students ability of design quality and design thinking.

Landscape Design is the perfect fusion of artificial factors and natural factors, human art and the rational combination of science and technology, Landscape Design course is different from the urban planning design and architecture design professional teaching category, from the Angle of the environmental art design, it includes the urban planning and design, architecture design, plant configuration and Landscape Design, water design, ecological design, and many other design content, is a new development in the field of environmental art design. After recent years of development, landscape planning course has been occupies an important position in the environmental art design major, teaching and achieved certain results, but because of the development of the time soon, the current environmental art professional courses in Landscape Design also has certain problem, the quality of teaching also has the very big development space.

In the unit teaching, Landscape Design class is usually in a professional basic course and interior design class before. Students through a series of interior space and the corresponding design practice, has formed relatively strong interior space, microscopic and meticulous way of thinking, and the use of perspective for the design of the visual expression way. Into the Landscape Design course, want to shift to more large-scale outdoor space design, especially in relatively more abstract plan for designing idea and expression, difficult to adapt to, on the scale of space form and spatial ability is weak, need to try to guide teachers consciously, make its sense and measure concept gradually formed outdoor places. [1] 


\section{The Specific Problems of the Current Domestic Landscape Design Course Teaching}

In recent years, the development of the Landscape Design course teaching, changing scientific research emerge in endlessly, applications continue to expand, to the current challenge the Landscape Design of the relatively fixed curriculum teaching mode, in both the course construction and teaching reform, there are many problems to be solved.

The Teaching Goal is not Clear. Due to the nature of the Landscape Design course has a multi-disciplinary overlapping, therefore, the domestic various colleges and universities on the basis of resource sharing advantages make full use of campus, the use of the existing related professional in different orientation to Landscape Design course curriculum. If placed in agronomy in the Landscape Design course, in which usually add more botanical knowledge; Placed under civil engineering professional Landscape Design class Cheng, usually join in the curriculum of civil engineering knowledge; And placed in the professional art of Landscape Design course, are usually more strengthen the knowledge content of art design class, etc.

The education way, combined with its own resources development Landscape Design in the Landscape Design education get diversified overall comprehensive development at the same time, also make Landscape Design course teaching goal becomes fuzzy not clear, and then for the Landscape Design of the teaching have brought many new problems. As in teaching how to find the equilibrium and balance the related discipline knowledge, avoid the barycenter offset of the course content; In the integration phase close subject knowledge make them supplement each other, how to adopt appropriate teaching methods, etc., will be a breakthrough point of teaching reform research.

Teaching Subject Simplification. In social practice, the content of the Landscape Design has a wide range, including residential area Landscape Design, square Landscape Design, urban park Landscape Design, the street Landscape Design, and other types. However, in the domestic Landscape Design of the teaching subject, often hard to make a choice, the various types of Landscape Design task and can only be one or two types of them to make specific training. This relatively single topic selection mode of teaching, to cultivate comprehensive and high quality practical type, Landscape Design talent, hard to do better meet the social demand for Landscape Design talent.

Single Teaching Method. At present, the domestic Landscape Design of the course is usually adopt the teaching methods of theory + design practice, for the Landscape Design of the relatively strong practical work, this kind of teaching method is too single, for many students real actual content is difficult to grasp. Such as various types of landscape space scale and the scale of the landscape space in difficult to accurately; Suffering of landscape space in the sense of reality In order to achieve real; On the Landscape Design of artificial environment color in photograph reflect with light color changes Difficult to intuitive feelings. [2]

Assessment of Course. Assessment way of simplifying assumptions is to examine the effects of course one of the effective means, is an important part in the teaching, but in the current domestic Landscape Design course examination way, basic limitations in due course design assignments this is relatively single traditional way. Due to the Landscape Design course with strong practicality and knowledge content of cross particularity, the single way of examination can not comprehensive, integrated, in-depth investigation of students learning the course of real and effective results.

\section{Teaching Resources}

The force at the core teaching is the teacher, "can a university without a building, but not without a master." University teachers are imparting knowledge and skills, also is the organizer of teaching activities, it is very important in the field of teaching.

Landscape Design itself is a continuously updated constantly adjust discipline, which requires the teachers of the landscape to constantly update knowledge reserves, strengthen study and practice. At the same time, the Landscape Design is a practical design ability training course, requires professional teacher has a strong ability of design practice, can guide students to modify and complete the project design. If teachers can carry on the design practice and students together, 
found the problem in practice and teaching, is a better way, which is now more advocate the "studio" teaching mode.

University learning, in addition to the education and guidance of teachers, more emphasis on the cultivation of the students' self-study ability and practical ability. Good university should give students as much as possible of learning materials, including rich content and comprehensive library and reference room; Advanced equipment and complete lab, model; High quality and strong pertinence practice base and so on. The practice of the central academy of fine arts school of architecture is to set up the teaching workshop, every workshop has the characteristics of a professional teacher, at the same time the construction of corresponding laboratory, such as decorative materials laboratory, laboratory furniture, chose the practice teaching base of Beijing architectural design institute, and considering the corresponding with mentors studio course content, in order to supplement studio teaching and perfect. Practice has proved that the establishment of this system can make to mobilize the enthusiasm of students' autonomous learning better, for the teachers and students to provide an open education teaching environment and development.

\section{A Variety of Teaching Methods}

Case Teaching Method. Before the subject design, introduce the knowledge of the subject design and method, help students understand the purpose of the study design, to design better. But in terms of art students, the study of the theory of pure is difficult to understand and not used. Application of case teaching method can turn a boring theory knowledge pertaining to the design case, through the case of interpretation and evaluation, deepen students' understanding of theoretical knowledge and memory, and to cultivate and improve the students' thinking in images.

As used in the case of teaching, to have certain representativeness and authenticity, reflect the content and forms of knowledge, can be a master of classical works, also can be a teacher myself involved in the practice project, the former has certain representativeness, can improve the students' design vision; Because the latter is a teacher's personal practice, to the project background and more detailed introduction of the design process.

It is important to note that the student for a master and classic case tend to have worship complex, teachers can not only the interpretation of total floor plan and rendering is a simple introduction and vague praise, should be through a series of analysis and design sketch, and a detailed description of the design process, to guide students from the aspects of function, structure, and art forms such as in-depth analysis and design, and rationally understand design where in the hell, where there is regret, and how to study masters of design thinking and design methods, training students the spirit of design research.

In addition, if conditional, organizes the student to an on-the-spot investigation of cases, you can let the students have a more vivid and comprehensive feel.

The Heuristic Teaching. Heuristic teaching mainly discuss teaching methods, promoting between students, teachers and students interaction and communication, has been shown to play a more conducive to students' initiative, using this method in design course. Change the habits of students passively waiting for the teacher to change figure, organize and launch a discussion, guide students take the initiative to explain their plan, other students some questions and published their own point of view, teachers guide series, the teaching method one can find problems of students in learning and understanding, second can cultivate the students' ability to analyze and solve problems, at the same time also can improve the students' ability of expression.

Simulation Teaching Method. Landscape Design is a complex integrated design process, including the design of a variety of factors to consider and balance of interests, builders, different users and designers position, focus on the content and also each are not identical, to the requirement of design in general, only through the interpretation of teachers, students consider in an all-round way and it is hard to balance. By role playing, simulation teaching method can make students more image understanding that may exist in the design of each game, and their common needs and different requirements for design, the debate between different roles can also help students to clear the factors must be considered in the design of and need to solve the problem, and can classify them 
according to how important they are and trade-offs, to get more suitable solutions. [3] This way of teaching the complex relationships and intuitive show in front of the students, lively and interesting, and is conducive to enhance the students' learning initiative, make students learn more flexible, grasp firmly.

\section{Process and Results of Teaching Evaluation}

Change the previous student hand in design work, the teacher feedback appraisal way for final grade. At the end of the course, organize students to display design, student is of your own or another's work to ask questions and discussion, the teacher to the student puts forward the solution in terms of functional, creative and artistic quality, let the students know their problem, not only has to let the students know how to deepen his design.

Design course should not only emphasize the end result, but also focus on the process of learning, focus on the process of design. Teacher evaluation standards should change the previous homework to the student result evaluation as the guidance, to process for examination and assessment of the results of the way. Evaluation of student learning process, to the student has a strong lead, motivate and control function.

All in all, as the core of the environmental art design professional backbone course, Landscape Design course has a special background of teaching. If you want to achieve better teaching effect need to be multi-pronged: micro scale such as city square Landscape Design and Landscape Design of residential area Landscape Design is more suitable for the teaching subject; Case teaching method, heuristic teaching and the application of simulation teaching method can effectively improve the teaching effect; The process and results of teaching evaluation method can better realize the design thinking skills, research ability and design ability "trinity" of the teaching goal.

Course Positioning is Not Clear, the Teaching Goal and the Actual not closely. For most did not distinguish between indoor, the direction of architecture or landscape environmental art design professional teaching, must choose a focus for teaching. Each direction, after all, the course content is very rich and profound, at this moment, how to grasp the direction of other professional courses, is the theory introduction, knowledge understanding, appreciation, is also to foster a certain design ability as the goal, then based on what level of target is appropriate? Both neither is too high, so effective, indeed for knowledge system, power system is perfect.

Mainly focus on the interior design of environmental art design major, although Landscape Design as the core of the environmental art design course, but it has no landscape the preamble of related courses, also do not have the follow-up courses. So the current state is formed as a "chicken ribs", the food tasteless, abandon a pity. 3 weeks course, 18 hours per week, time

Short, wide range, content, component, and students never contact the related content, want to alone in the classroom training out of the strong ability of design is almost impossible task. Give up, but not face in the future work is likely to face a big chunk of the content, the lack of a lot of knowledge and skills, also lost a lot of employment opportunities.

How to locate courses, positioning it in the position of the whole teaching system, it is how to achieve the goal of, meet do not conform to the social demand form at present, under the conditions do not conform to the students' learning, can promote students' employment, this is what we should think more.

The Teaching Contents Need to Streamline, Teaching Materials and Curriculum Construction Lag. There are no perfect teaching material, the course used some teaching material is not too deep, is too shallow, or not and match them with the teachers' teaching content, teacher often said, the content of the practice of the book, students don't even look at the teaching material, even without textbooks, students are even more reluctant to his teacher, according to the teaching material. And the old teaching material content has apparently couldn't keep up with the situation, content and more deep, case pictures are older.

Used to offer a wide range of Landscape Design content of the course covers, including the city square Landscape Design, the street Landscape Design, tourism scenic area landscape, residential environment Landscape Design, Landscape Design of commercial pedestrian street area, and so on, 
but are due to class time limit, tasted, students learn knowledge, often also is very shallow, practical ability is weak, and in the face of the market demand is not really up to the most extensive residential area Landscape Design, so for this kind of phenomenon, reform the teaching content, change the teaching focus, strengthen the special training, is imminent, the key is how to optimize the teaching content, how to choose the suitable teaching methods in higher vocational colleges.

The Single Teaching Methods, Examination Methods, the Teaching Effect is not Prominent. In the past "Landscape Design" teaching, the traditional teaching methods, assessment of single mode is still dominant. The traditional teaching method, teaching in teachers as the center, with knowledge and theory of infusion is given priority to, the lack of interaction between teachers and students, the lack of combined with the practice, the students' interest in learning, to reach a good teachingLearning effect, cultivated students' actual operation ability is poor.

Examination form is too single, and on the topic of setting biased towards the water Landscape Design, $3 \mathrm{~d}$ landscape rendering performance is given priority to, such as the deviation in the water Landscape Design and $3 \mathrm{~d}$ software assessment of the operation mode, one is all use software for large landscape rendering performance is also difficult for students, increased the difficulty of the performance, the second is not in the form of performance and the major form of most of the Landscape Design company, inspection can't line with employment ability request, three are also failed to assess the students' real level, not to promote learning, promote students' mastery of professional skills, improve professional competence.

"Landscape Design" as a practical and operational courses are strong, the teaching methods and examination form affects both the improvement of teaching quality, also violated the higher vocational colleges to strengthen the students practical ability.

The Students Ability of Comprehensive Design Performance. Many students (including students) lack of full understanding of the landscape industry. For example of landscape project from design to take over the whole process of construction, procedures and requirements are not completely clear; To understand the social situation of landscape industry and know enough: design the basic theory of master not even some strange, space design is a lack of sharpness, sometimes cannot accurately judge the merits of the planning and design of a space. [4]

The design of the students in poor expression ability, expressed in paper: the drawing expression, cannot master the writing design method, the format design not beautiful, is not in conformity with ' the style of design, exhibition board, and text layout form and content are not clear; Oral communication, students often don't know how to go to introduce themselves by partyCase, how to communicate with party a, and even ignore the importance of communication.

On the design, because the understanding of the landscape industry, less students cultural quality and insufficient, design often become a mere formality, the lack of connotation. What's more, don't realize the meaning of design conception, just simple function layout design.

Lack of communication with the people, the spirit of collaboration, and handling. Because the student is in previous teaching, the majority of practice for the unit with the personal practice, the lack of team cooperation training and special training, causes students of personal ideas and the lack of the spirit of unity and cooperation, don't know how to coordinate work, thus affect the quality of the Landscape Design works.

\section{The Teaching Reform of Landscape Design Practices and Methods}

Clear Course Orientation. Always with interior design as the main body of the cultivation system, the landscape design should be as a knowledge system, and the ability of ascension, rather than in the professional study focus. This course on the basis of theoretical knowledge introduction, trains the student to have the basic landscape concept, basic design ability as the goal. Specifically understand landscape basic concept, preliminary understand the general rules and operation method of landscape design, able to draw up the plan drawings, fluent write design specifications, within the prescribed time to complete a small project design. Clear positioning and course objective, can according to the unified course group teaching direction, the corresponding teaching reform. 
Pay Attention to Cultivate the Students Ability of Space Imagination and Reasoning. Landscape Design fundamentally is also the space planning, students from the interior space into broad space to outdoor, because the landscape space is not completely closed and clear definition, students are difficult to grasp the space. Therefore, in this course should pay attention to the cultivation of the spatial ability, as well as the students themselves according to the life experience and feeling in spatial reasoning ability. [5]

The Course Content Filtering and Streamline. According to the needs of society, students' experience and employment after the majority of facing the type of work, to select the project of residential landscape series of teaching content, 1 layer, in stages to carry on the teaching. Residential area Landscape Design as the core, radiation of other types of Landscape Design. In the residential Landscape Design also covers a large number of other types of landscape, such as the central plaza, Landscape Design, waterscape design, garden design, facilities, etc., so in the residential area Landscape Design for the teaching emphasis in the design of teaching content, also can let students in a unified whole residential area landscape planning, learning and experience all kinds of types and characteristics of Landscape Design. Thus, reach to point with surface, roaring toward the enemy, digging, mastering many skills while specializing in teaching goal.

After we adjust the teaching content and progress, made the four levels and the special teaching.

The Copy is Given Priority to Private Courtyard Design. The plan of the first copy the courtyard design, understand the landscape elements in the drawing, space demarcation method and so on, then according to the design elevation, floor plan realize the change of the stereo space height, draw the rendering

The Independent Design-Private Courtyard Design. Designed by copying stage to autonomous practice, experience on project teaching of knowledge, preliminary attempt to use Landscape Design principles and methods, from passive to active thinking.

Discuss Analysis-Residential Area Landscape Design. By thinking of his own plan, to the analysis of the existing design plan, learn to find problems, thinking, put forward the solution.

Group Cooperation-Residential Area Landscape Design. Into the project team, the simulation design company operates, cooperative design of residential area landscape, to achieve independent innovation.

At the same time, comply with the characteristics of the Landscape Design performance, and Landscape Design company general hand-painted give priority to adapt to the current situation of actual performance, performance in landscape, students are required to use the hand the form of performance, combined with computer software modifications and layout post-production.

Teaching Method Improvement. The Goal to Promote Process Method. At the beginning of class, must pay attention to the first class, in this not only to solve the basic concept and principle, the first thing to let students clear what this course to teach, what they should learn, what they can achieve level after this course, should achieve what level, what about future work of learning to help... Clear learning objectives, would greatly improve the initiative of the learning process.

Advanced Method for Different Levels of Competency. Divide teaching content into different levels, from copying to create, by learning to evaluate, hierarchical teaching, meet the students' knowledge level and ability.

Project Driven Method. In the design of teaching content and practice project to project course. Using real or virtual project, to guide the student to the understanding of curriculum knowledge to master, to the design of the exercise ability. In the teaching of basic theory, then practice in middle school, learn in grasp, grasp in the enlightenment, after mastering performance.

Practical Teaching Method. Landscape Design is a practical, comprehensive curriculum, high pure theoretical teaching in the classroom can't improve the students' learning interest and enthusiasm, also can't let students have the real practice of Landscape Design. Increase practice teaching in the subject, lead students into the real environment, landscape, space, know plants, improve the actual effect, improve the students' interest in learning."Practice teaching" method, there are two main aspects:

Xiaoshan training base, one is to conduct site practice, by teachers in combination with the 
teaching content, configuration of landscape and plants in the explanation and comment, guide students to plant design and landscape construction.

Second, screening of the typical case to students, to carry on the simulation study practice. By the students in small groups as the unit of case discussion, put forward their own design, class discussion, as a group for the unit to power group scheme. The last teacher reviews, points out the advantages and disadvantages of each scheme. In this way, to learn.

Participation, training students use knowledge in thinking, problem solving skills, also can exercise the students' oral expression ability.

Scene Simulation Teaching Method. Teacher asked the students at the completion of a design case, make atlas layout, and computer demonstration, assuming that report design scenario, the student to carry on the corresponding role playing, and according to the design of the learned knowledge to explain, reporting, necessary guidance teachers from teaching method. This simulation training can exercise the students' oral expression ability, team cooperation ability, to learn more about the company design, increase of actual combat experience, active classroom atmosphere.

Transformation of Assessment Methods. On reform of examination mode, change the single assessment mode. According to the requirements of the Landscape Design practical ability and the teaching purpose, combined with the actual situation of students' learning, to take the test in the form of diversification, the form of group, division of labor cooperation scheme design, and layout, make text printing solutions. Which requires students to use hand-drawn and computer combination of performance, and an analysis of the reasonable design scheme, and writing the design specification.

Procedural Examination. Examination form, the grades was $60 \%$, the final grade is $40 \%$, pay attention to the performance at ordinary times, think peace job completion.

Final grade comprehensive, the following evaluation: design originality, design, modeling design performance (hand-painted, computer), design specifications, design patterns and printing effect, the design of cooperation.

Assessment Content and Way of Students Comprehensive Quality in Comprehensive Evaluation for the Purpose, and not to a Test Set. On the inspection content, not only confined to the content of the teaching material, and should pay more attention to the appraisal of students' innovative thinking and ability. Appraisal of drawing should not be confined to the assessment of students' application of a certain tool, but to let the students the freedom to choose, and then integrated all aspects to conduct a comprehensive evaluation for students. In the mode of examination, the implementation of the "three combination" way of appraisal, namely the combination of theory and experiment of examination, concentration and examination of dispersed phase, the final exam peace ability appraisal. The combination of the above for the Landscape Design course teaching reform measures, arouse the enthusiasm of the students' learning, and received good results.

To Explore the Reform of Teaching Modes. The Integration of Theory Teaching and Practice Teaching. As the design of practical courses, theory teaching and practice teaching are inseparable, especially for higher vocational colleges, practice is key.

The Classroom Teaching and Extracurricular Studio Integration. We founded the art studio, led by professional teachers guidance, virtual project exercise regularly, not real project design on a regular basis, although the teacher's investment increased, but greatly contributed to the student's enthusiasm.

The School Teaching and Training Outside Integration. School was founded in xiaoshan landscape practice base, teaching can adopt the way of practice base for thrust, combined with social environment landscape practice at the same time, the effect is better.

Design and Production Integration. Design results, requirements expressed through a certain form, including panel, model, text books, power point, etc. 


\section{Conclusion}

After thinking of the teaching reform, the author put them into teaching practice and inspect these ideas of practice which is effective and can improve the students' professional skills. Due to the closer to the actual course content which is more concise, method of teaching for students is much easier to accept; combining the practice project with the multimedia teaching, and the case analysis, targeted follow the development of the market, cooperating with practice on landscape, which improved the students' learning enthusiasm, also added a employment channels. Of course, these measures still need to improve, the exploration of teaching reform will continue. In order to improve the quality of education, Landscape Design must be under the guidance of spirit of innovation, going on change of teaching, all-round, multi-angle exploration, to establish perfect interior design teaching system from the requirement of social development of talent quality interior design.

Pay attention to exploration and innovation of the teaching mode, foster strengths and circumvent weaknesses, create characteristic, also pay attention to the improvement of the interior design teaching method, improve the quality of teaching constantly, make interior design teaching adapted to the development of The Times.

At the same time, also make students with the cultivation of a diverse teaching pattern of the Landscape Design improve the appreciation ability on landscape and landscape aesthetic and open their eyes, and ultimately create a good Landscape Design works with a strong taste of new era.

\section{References}

[1] Pan Wu-hua. Indoor display art design. Beijing, China Building Industry Press, 1999

[2] Yan Wen-Ming. Modern indoor display art is analysed and the relationship between the people [J]. China Science and Technology Expo 2009 (14)

[3] Zhang Wei-wei. Display is analysed the meaning of art in the indoor environment [J]. New Finance and Economics (theory), 2010 (6)

[4] Cheng Kun. Environmental art design professional practicality teaching exploration [J]. Information Science and Technology, 2009 (10) : 732

[5] Ma Rui-dong. The scientific environmental art teaching in colleges and universities study [J]. Philosophy and the Humanities, 2009 (8) 